\title{
The Analysis of Stress Distribution on the Physical Model of Road Base Layer
}

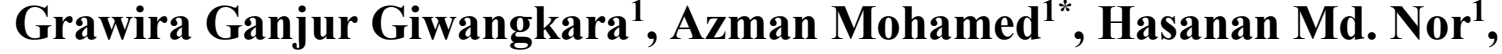 \\ Nur Hafizah A. Khalid ${ }^{1}$
}

${ }^{1}$ School of Civil Engineering, Faculty of Engineering,

Universiti Teknologi Malaysia, 81310 Skudai, Johor, MALAYSIA

*Corresponding Author

DOI: https://doi.org/10.30880/ijie.2020.12.08.033

Received 22 March 2020; Accepted 16 May 2020; Available online 15 September 2020

\begin{abstract}
The road base layer as a primary foundation for the flexible pavement needs to provide adequate strength for the working load. The road base layer which is constructed from a gradation of aggregate must distribute the stress as wide as possible to reduce the load per square area. The action of stress distribution on the road base layer mostly relies on its grain-to-grain interaction. This research used the natural crushed aggregate (NCA) and the recycled concrete aggregate (RCA) as the road base materials. Physical models were conducted to evaluate the stress distribution under a static load. The physical model was using a box with a dimension of $620 \mathrm{~mm} \times 620 \mathrm{~mm} \times 500$ $\mathrm{mm}$. There were three layers for the physical model such as the road base layer, sub-base layer, and subgrade layer. The thickness of each layer was $200 \mathrm{~mm}, 100 \mathrm{~mm}$, and $200 \mathrm{~mm}$ respectively. A static load with a maximum of 20 $\mathrm{kN}$ in the increment of $1 \mathrm{kN}$ was added. The result of the scaled-model was not as similar to the theory of Boussinesq related to the stress distribution. The characteristic of the materials will show a different behavior of the stress distribution.
\end{abstract}

Keywords: Road base, stress distribution, recycled concrete aggregate

\section{Introduction}

The road base layer is a layer between the wearing surface (pavement) and the sub base in the road structure hierarchy which functions to distribute traffic load to the subsequent layers. This layer conventionally constructed by using gravel soil, crushed natural aggregate (NA), natural crushed aggregate (NCA), or stabilized materials that are extracted from natural resources. The availability of the NCA as the most common type of aggregate for civil construction must always be under control. An alternative material for the NCA must be taken, especially for those countries which do not have natural resources. Hong Kong which is a lack of natural resources for NCA needs to recycle and re-use some 20 million tons of construction and demolition waste (CDW) each year [1]. In 2018, Singapore had a construction waste of more than 1.6 million tons which almost $99 \%$ of it successfully recycled [2]. The latest survey in Malaysia shows that $28.3 \%$ of waste was the CDW. Meanwhile, $65.66 \%$ of it was the aggregate and concrete waste [3]. One of a good application example for recycling the CDW to be the recycled aggregate known as recycled concrete aggregate (RCA) is coming from Japan. Almost $96 \%$ of recycled aggregate in Japan is used for road bedding because it can save a lot of resources [4]. The utilization of the alternative material for the road base layer has been conducted over the past decade. RCA as a leading material for NCA replacement still needs a lot of improvement to equalize the road base layer performance from the NCA. 
A typical flexible pavement consists of surface, road base, and sub-base built over compacted subgrade or natural soil which met the requirement [5]. The road base layer is a layer directly under the surface pavement. The material for the road base layer is typically the unstabilized aggregates. The strength of the road base layer relies on its compactness and mainly from the grain-to-grain interaction to transfer the load from the surface [6]. Therefore, in some cases, the aggregate for road base could also be stabilized with asphalt, Portland cement, or other stabilizing materials to improve its strength. In the flexible pavement, the load only considered from one acting wheel of a vehicle because the working load will be localized (one side on one axle) [7]. According to the Malaysian Public Works Department, the material for the road base layer must be hard, durable, clean, and essentially free from clay and other deleterious materials [8]. The road base material shall be crushed rock, crushed gravel, or a mixture of crushed rock and gravel. But now, the recycled concrete aggregate (RCA) already become an alternative material for the road base layer. In Western Australia, a project was conducted to evaluate the application of the RCA as a road base material. Even though the RCA is likely to give an increased asphalt fatigue life, but it can provide a good quality road base for road [9]. On the other aspect, the application or the RCA as the road base material may provide a good economic benefit, especially when the material source is nearby the construction site [10].

As the main foundation for the flexible pavement, the road base layer must be strong enough to hold the working load no matter it was constructed from NCA or RCA. The main problem for the RCA to be used as the road base material is about its strength, whether for the individual aggregate grain or in a compacted layer compared to the NCA. Many aspects affecting the RCA strength, but mainly the lack of its strength because of the mortar attached to the rock. The principle for the road base layer to obtain its strength is from the grain-to-grain action of the aggregate as the construction material. The grain-to-grain action distributes the working load to the wider area. The mortar attached to the RCA may break and cause a slip between the aggregate and mess up the load dispersion. Eventually, it will affect the whole layer. Therefore, the stress distribution from the working load on the road base layer is playing a very important role.

The road base is designed and constructed to provide a uniform and stable support for the surfacing course and its load. The vehicle and its load will be transferred into the pavement. The stress distribution on the pavement construction usually adapting the theory from the soil mechanics. Many formulas based on the theory of elasticity have been used to compute stresses in soils. In 1885, Boussinesq solved the problem related to the stress distribution due to a surface load [11]. Later then, Westergaard (1938) also proposed a theory related to the stress distribution. In practice, many geotechnical engineers often prefer the Boussinesq approach primarily because it gives more conservative results while the Westergaard's is often preferred when calculating stress distribution in layered soils. Both of the theory based on some assumptions and the differences between one or the other theory are small and considered less significant [12]. The implementation of the stress distribution theory on the cohesionless soil such as aggregate may have a different result. Hence, an experiment must be carried out to evaluate the stress distribution of the road base layer. The objective of this research is mainly to evaluate the stress distribution of the road base layer by comparing the physical model measurement result in the theory. Soil pressures were placed under the road base layer on the physical model to obtain the stress under a static load.

\section{Research Material}

Two main materials for this research were natural crushed aggregate (NCA) and recycled crushed aggregate (RCA) as the road base materials. The RCA was produced from the concrete waste in Universiti Teknologi Malaysia with a minimum of $30 \mathrm{MPa}$ strength. The strength measurement was using the rebound hammer test method as it was practical for in-situ operational. While the NCA was taken from a crusher plant in Johor, Malaysia. The static load tests were conducted in Highway and Transportation Laboratory of Civil Engineering, Universiti Teknologi Malaysia. Some properties were given from previous research such as specific gravity, water absorption, maximum dry density (MDD), and optimum moisture content (OMC) [13]. Sub-base and subgrade were not the main focus on this research, hence, the parameter taken from those only the California Bearing Ratio (CBR) value as the representative for compacted material strength. The sub-base in this research was using a mixture of sand and $20 \%$ of NCA retained at $20 \mathrm{~mm}$ of BS 1377 sieve. This mixture can be assumed that the whole material will have a CBR value of $30 \%$ [8]. The soil for subgrade material was oven-dried and sieved for passing the $2.0 \mathrm{~mm}$ sieve. This sieve size was chosen because it preserved most soil aggregates while leading to uniform particle size and removing larger organic debris and stones. Also from historical reason, Atterberg sets the soil $>2 \mathrm{~mm}$ considered as gravel in his particle scale. This scale then accepted as an international system [14].

Road base material must meet the requirements from the country in which the road will be constructed. The Malaysian Department of Public Works has stated that there are seven quality requirements for road base material in Standard Specification for Road Works Section 4 [8]. Previous research has conducted some properties tests [13] and some repeated tests also been conducted to obtain better data. The results are provided in Table 1 and Error! Reference source not found..

None of the NCA or RCA meet the gradation envelopes as these materials come from its natural states. Thus, the NCA and the RCA must be graded according to the requirement apply. The concern related to the RCA properties is the condition before it was shaped into an aggregate. Different mixtures of concrete will affect the properties of RCA even 
for a small difference, especially for the physical properties. In this research previously, the RCA has a specific gravity (SSD) of $2,420 \mathrm{~kg} / \mathrm{m}^{3}$ [13] while research from Bhuiyan shows a slightly different value of about 2,480 kg/m 3 [15]. A slightly different result also occurs in water absorption. The previous result shows $5.51 \%$ whereas the research from Zhu shows a value of $4.90 \%$ [16]. The difference values of those properties are related to the original condition of the concrete before crushed into aggregate shape. The original condition of the concrete includes its compressive strength, aggregate gradation, binder quality, and additional substances such as a concrete hardener.

Table 1 - Properties of NCA and RCA

\begin{tabular}{lccl}
\hline \multicolumn{1}{c}{ Description } & NCA & RCA & \multicolumn{1}{c}{ Requirement } \\
\hline Aggregate Crushing Value (ACV) & $24.14 \%$ & $31.56 \%$ & Less than $25 \%$ \\
Flakiness Index & $15.50 \%$ & $12.10 \%$ & Less than $25 \%$ \\
Soundness & $0.50 \%$ & $2.57 \%$ & Less than $18 \%$ \\
CBR Value & $86.23 \%$ & $108.88 \%$ & Minimum of $80 \%$ (95\% compaction) \\
Sand Equivalent & $66.70 \%$ & $92.50 \%$ & Shall not less than 45\% (passing 4.75 mm) \\
\hline
\end{tabular}

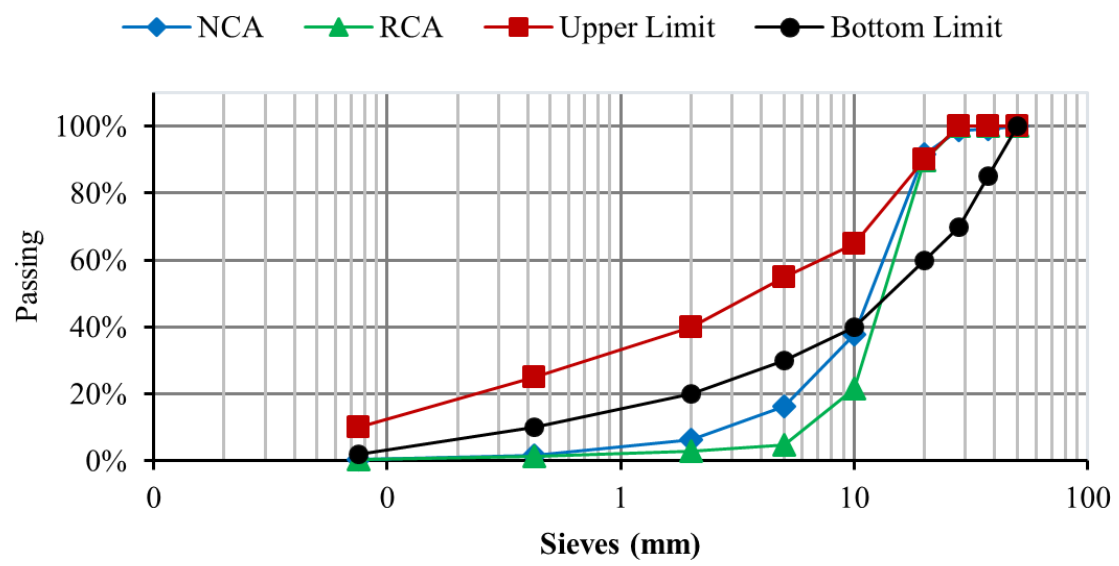

Fig. 1 - Sieve analysis of the original gradation of NCA and RCA

\section{Methodology}

\subsection{Scaled Model for Static Load Test}

The scaled model was using a transparent box with a dimension of $62 \mathrm{~cm}$ x $62 \mathrm{~cm} \times 52 \mathrm{~cm}$. From top to the bottom were road base, sub-base, and subgrade with a thickness of $200 \mathrm{~mm}, 100 \mathrm{~mm}$, and $200 \mathrm{~mm}$ respectively. The thickness of the layers was based on the traffic load and subgrade quality. The road base thickness was obtained from previous research [17] which based on the requirement from ATJ 5/85 of the Malaysian Public Works Department [18]. The requirement also stated that underneath the bituminous pavement courses, a minimum combined thickness of granular road base and sub-base of $300 \mathrm{~mm}$ and a minimum thickness of granular road base of $200 \mathrm{~mm}$ is used for all traffic categories. It means that a $100 \mathrm{~mm}$ of thickness for sub-base can be used under designer discretion. In this research, the subgrade CBR value also assumes more than 30\% from category T5. The scaled model used a static load in a circular plate with a diameter of $112 \mathrm{~mm}$ which means the contact area is $0.0098 \mathrm{~m}^{2}$. A load pressure cell was placed at the center of the surface and two soil pressures were placed at the center-bottom and 45 degrees from the center of the road base layer as seen at Fig. 2.

The load was added until a maximum of $20 \mathrm{kN}$ in $1 \mathrm{kN}$ incremental. With the diameter of $112 \mathrm{~mm}$ of the circular plate as the surface pressure area, the maximum pressure that can be achieved is $2031 \mathrm{kPa}$. The tire inflation pressure has been used as a contact pressure for the ease of calculation. A report from many kinds of research [18, 19, 20] uses a range of $520 \mathrm{kPa}$ to $1000 \mathrm{kPa}$ each tire for the tire inflation pressure. The higher pressure used in this research was simply to gain more data collected as the sample also being used for other research data collection. The soil pressures have a diameter of $46 \mathrm{~mm}$ which means the contact area is $0.0017 \mathrm{~m}^{2}$. The thickness of the soil pressure is $10 \mathrm{~mm}$.

\subsection{Stress Distribution Analysis by Boussinesq Theory}

The load distribution from the surface can be simply calculated using a 2:1 method [12]. This method is using the principle of load distribution in soil engineering. This method assumes that the distributed load over an area increases in width in proportion to the depth below the loaded area. Note, the 2:1 distribution is only valid inside (below) the footprint of the loaded area and must never be used to calculate the stress outside the footprint. The first trial to modeling the stress distribution in soil has been to assume soil to be a perfectly elastic body. The formulation itself was solved by Boussinesq 
for a vertical point load. Some assumptions were made in the solution such as the soil is elastic medium, homogeneous, isotropic, and semi-infinite [11]. From Fig. 3, the stress at a certain point $\left(\sigma_{z}\right)$ can be obtained from Equation 1 where $K$ is the influence factor ( $K_{B}$, for Boussinesq influence factor), $Q$ is single concentrated vertical load, and $z$ is the depth. Influence factor is a function of $r / z$ which is dimensionless. The function of the influence factor is shown in Equation 2. The equation of vertical stress due to point load can be extended to obtain the vertical pressure under the uniformly loaded circular area from the variables of the radius (a) and load per unit area (q). The concept is to divide the circular area into small parts. In Fig. 4, a darkened area $(\delta A)$ is a small part of the whole circular area. The load on that area will be $q \delta A$ and may be considered as a point load. The total vertical pressure at some point of depth (z) in the Boussinesq theory is given in Equation (3).
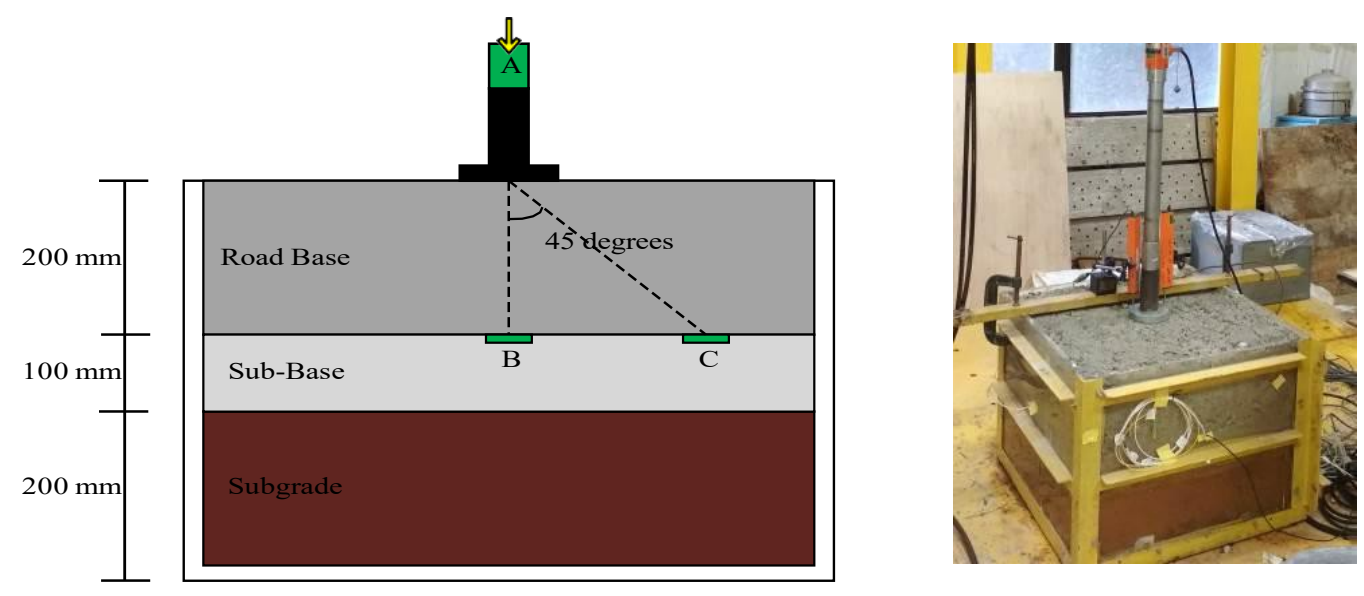

Fig. 2 - The scaled-model setting for the static load test. A is load pressure cell while B and C are the soil pressures

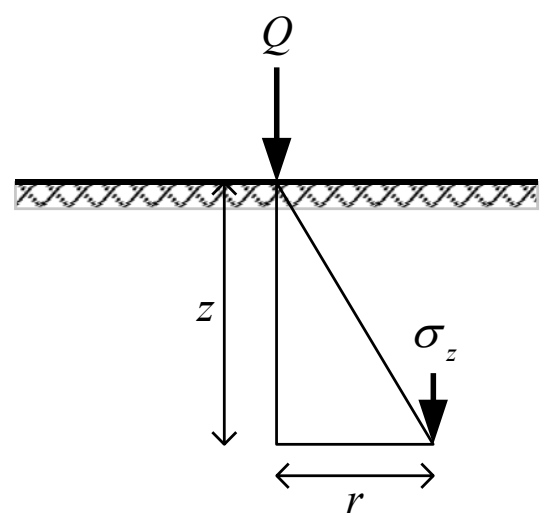

Fig. 3 - Point load in Boussinesq Theory

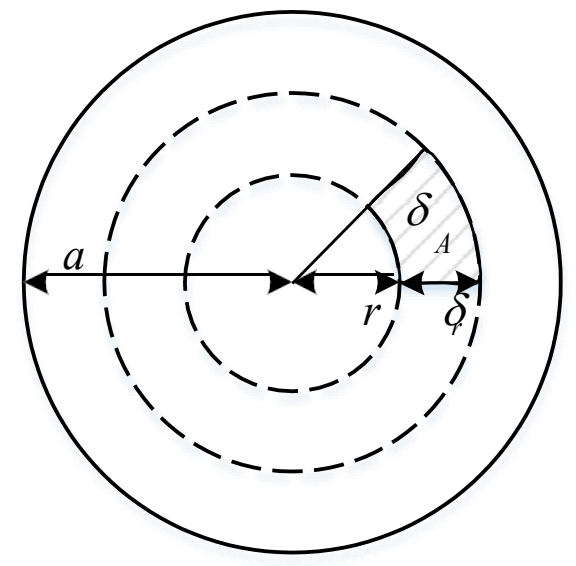

Fig. 4 - Uniformly circular load in Boussinesq Theory

$$
\begin{gathered}
\sigma_{z}=K \frac{Q}{z^{2}} \\
K=K_{B}=\frac{3}{2 \pi}\left[\frac{1}{1+\left(\frac{r}{z}\right)^{2}}\right]^{5 / 2}
\end{gathered}
$$




$$
\sigma_{z}=q \cdot K_{B}=q\left[1-\left\{\frac{1}{1+\left(\frac{a}{z}\right)^{2}}\right\}^{3 / 2}\right]
$$

\subsection{The Rock-Mortar Ratio in Recycled Concrete Aggregate (RCA)}

The evaluation of the rock-mortar ratio for RCA was using manual determination. The researcher's ability to differentiate between the mortar and the rock is the sole decision-maker. The principle of this test is calculating the area of rock and mortar to obtain the ratio. A mixture of RCA was cast into a cemented block. The red color cement was used to help differentiate the RCA and the cement. Once the block is hardened, then it was sliced into two-part. Each part then goes to the desktop scanner and manually marked the rock-mortar area by using a software AutoCAD. The software can determine the area of the rock or the mortar directly from the picture. The areas of the rock and the mortar were assumed to be the portion of each part. See Fig. 5 below.
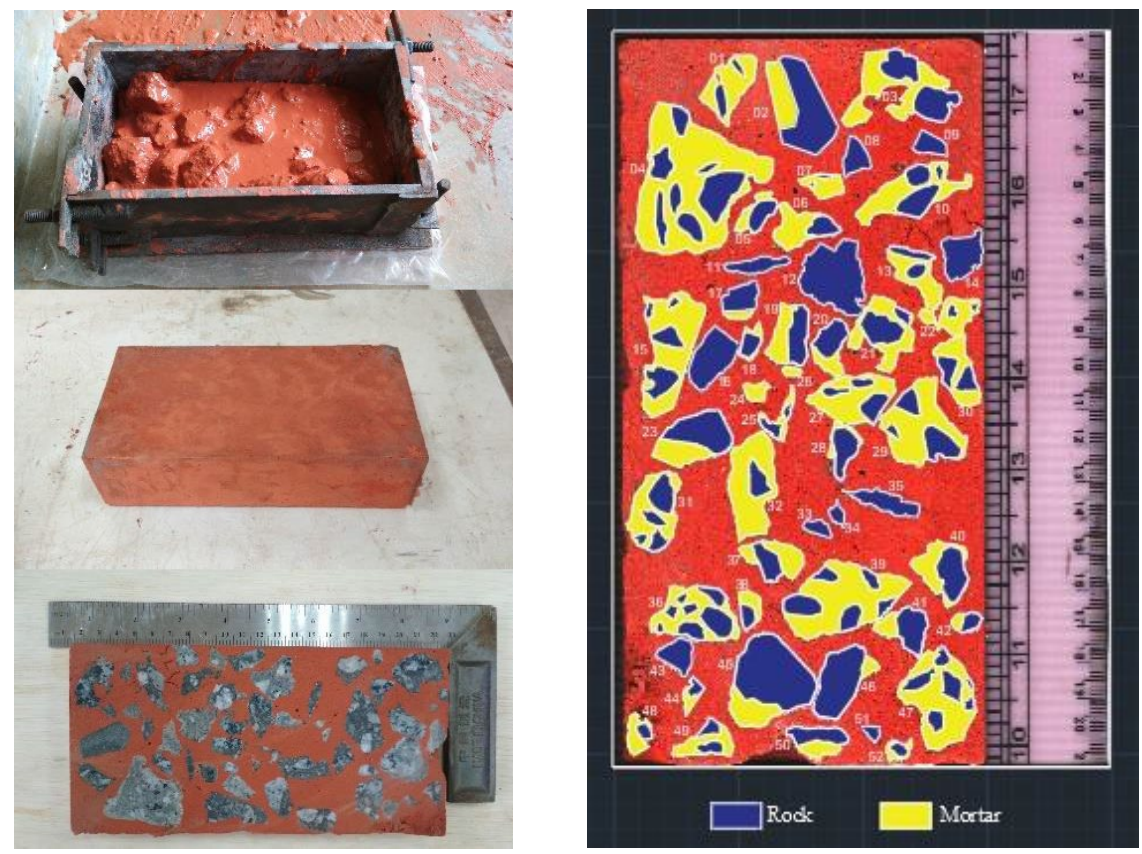

Fig. 5 - (a) RCA was cast into the mold, taken out from the mold, and sliced into two parts (b) sample evaluated by using AutoCAD software

\section{Results and Discussions}

The result of this research is divided into three main results, firstly the result obtained from the readings of the soil pressures as the static load occurred, secondly the calculation of the pressure at the center-bottom and 45 degrees from the surface center of the road base layer based on the Boussinesq theory, and thirdly, the ratio between the rock an mortar in the RCA. The data for calculation for Equation 3 is shown in Table 2 which is the same for the sample from NCA and RCA.

Table 2 - Value of a and $\mathrm{z}$

\begin{tabular}{lc}
\hline \multicolumn{1}{c}{ Description } & Value \\
\hline The radius of the circular area $(\mathrm{a})$ & $0.056 \mathrm{~m}$ \\
Distance from the surface to the soil pressure & $0.19 \mathrm{~m}$ \\
Ratio $(\mathrm{a} / \mathrm{z})^{2}$ & 0.0869 \\
Surface load $(\mathrm{P})$ & $\underline{0-2031 \mathrm{kPa}}$ \\
\hline
\end{tabular}

The result of the center-bottom pressure for road base layer from NCA and RCA are presented in Fig. 6. The point on the 45 degrees from the surface center has a distance (r) of $144 \mathrm{~mm}$ or $0.144 \mathrm{~m}$. By using Equation 1, the results for the point of 45 degrees from the surface center are presented in Fig. 7. The center-bottom pressure of the road base layer 
from the NCA had a slightly lower value compared to the road base layer from the RCA. Only $18.9 \%$ of the surface pressures on average were obtained, whereas the road base layer from RCA obtained 19.3\%. The bottom pressure at the 45 degrees from the surface center for both NCA and RCA shows a similar result which is around $1.2 \%$ from the average surface pressures. It means that the road base layer from the RCA has more pressure passing through the aggregate layer compared to the road base layer from NCA.
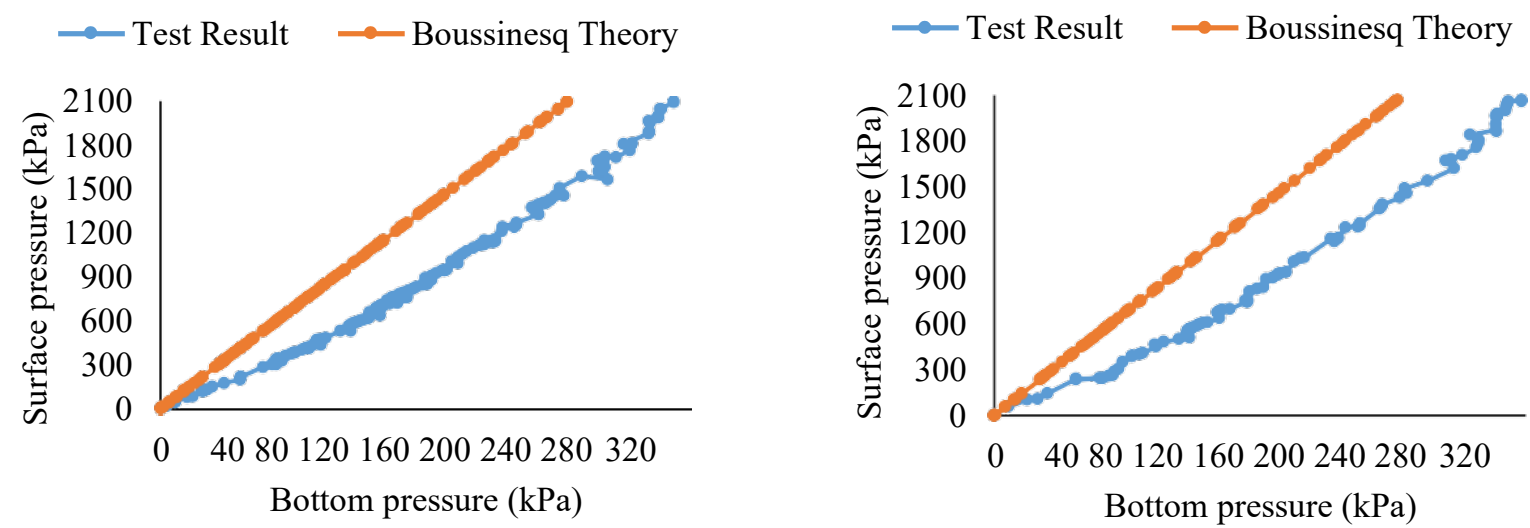

Fig. 6 - Result for the center-bottom pressure of the (a) NCA and (b) RCA as road base material
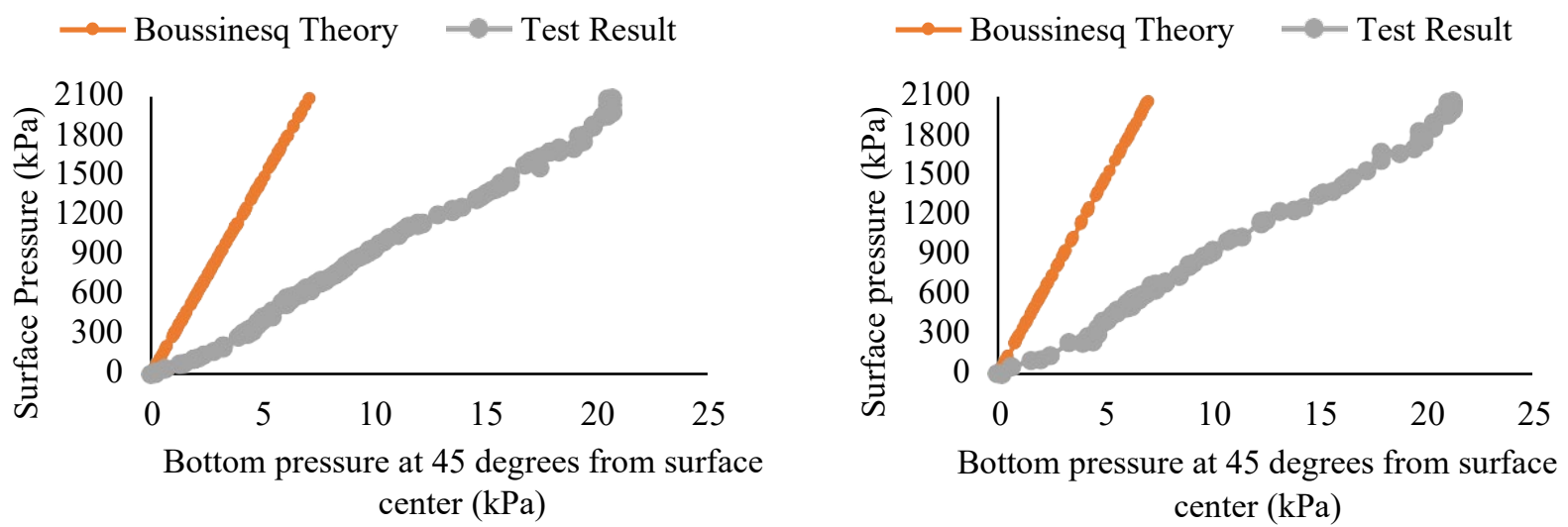

Fig. 7 - Result for the 45 degrees from center pressure of the (a) NCA and (b) RCA as road base material

Measured stresses from both points and samples of the scaled model showed higher results compared to the theory. In this scaled model experiment, the pressures at the bottom of the road base layer were $61.2 \%$ and $64.1 \%$ higher compared to the Boussinesq theory for NCA and RCA respectively. Whereas the bottom pressures at 45 degrees from the surface center were $244.9 \%$ and $249.4 \%$ higher compared to the result of the Boussinesq theory for NCA and RCA respectively. Robert F. Schiffman stated that in most cases the recorded results of the experimental model were in the range of, or higher than, the homogeneous analysis of Boussinesq [21]. There were three major interpretations according to why the result is different. First, even in the soil mechanics itself, the stress distribution theories were not solely accurate to determine the pressure underneath the soil layers. Assumptions such as the soil is an elastic medium, homogenous, isotropic, and semi-infinite were used to generalize the condition of the soil which is not enough to predict the stress distribution behavior as each type of soil has its specific characteristic. An expanded theory stated that outside those assumptions, the adhesion of the contact area between the tire and the surface of the pavement may also affect the stress distribution in a dynamic load. Not to mention the adhesion between the material itself, such as soft soil or clay. The influence of the surface adhesion will cause a lateral restriction and reduce the vertical pressure [22]. In this research, a static load with a smooth surface of the circular plate will provide a frictionless contact to the surface of the noncohesive aggregate. Thus, the vertical pressure will be greater compared to the Boussinesq theory as the pressure was more concentrated in a vertical direction.

The second interpretation is about the heterogeneous and anisotropic characteristics of the road base material. Those characteristics also contribute to the different results between theory and laboratory experiments as it will be difficult to predict the distribution characteristic [23]. Buisman's analysis shows that the anisotropic effect on the material may increase the stress depends on the ratio between the elasticity $(E)$ in horizontal and vertical directions. If the ratio is $<1$, 
then higher stress at the bottom of the layer is expected to be increased until several hundred percent than those isotropic materials [21]. The layer of aggregate which has a larger void compare to soil may also contribute the difference. The shape of the aggregate which is various also has a contribution to the result. The grain-to-grain movement of the aggregate cannot be predicted as smooth as the soil. Moreover, the RCA is a combination of rock and mortar which have a different characteristic compare to the NCA. The difference characteristic of those aggregate types led to a slightly different result, even though in general, they have similar behavior if compared to the theory. From the rock-mortar ratio analysis, it was found out that the content in RCA is $57.9 \%$ rock and $42.1 \%$ mortar. It means that more than half of the RCA grain is a mortar that has a lower density compared to rock. In the CBR value from the laboratory test, this situation makes the RCA very ease to broke and fill the gap. Therefore, the CBR value of the RCA is higher compared to the NCA. Whereas as a road base layer that has a wider surface and thickness, the compaction maybe has a different result. Even though it might be compacted as the same as the laboratory compaction, but when pressure from the load applied, the RCA grains are moving and the attached mortar on the RCA becomes the weakness. The mortar is easy to peeled off or broken, and in the end, the strength of the road base layer will decrease.

The last interpretation related to the higher value of the experimental model to the theory is about the sample design. Although the free space surrounding the pressure plate is more than two times its diameter (if circular), still the rigid boundary may affect the stress distribution. Biot's analysis for a single layer soil with a rigid boundary shows that the normal stresses (particularly under the load) are substantially higher than the corresponding Boussinesq theory [24]. According to Biot, the stress beneath the load was 1.56 times the Boussinesq theory or $56 \%$ higher. It corresponds to the results of the center bottom pressure on this research for NCA and RCA.

\section{Conclusions}

The conclusion from this research is the road base layer from the NCA has a better stress distribution compare to the road base layer from the RCA. The grain-to-grain action of the NCA shows a better interaction in handling the surface pressure. The mortar that attached to the RCA has become the main weakness for the road base layer strength. The content of the mortar which almost half of the aggregate size makes the RCA has difficulty withstand the pressure. In the end, bad interaction between the RCA also makes the surface pressure can not be well distributed to the wider area. The CBR result from the laboratory test does not show the same result in the scaled-model. When it is implemented in the real project, some improvements must be conducted to make the RCA at least have a similar performance compared to the NCA. Further research must also consider the characteristics of the aggregate when using the theory from soil mechanics as the assumptions will be different.

\section{Acknowledgment}

Sincere thanks to Universiti Teknologi Malaysia for financial support from High Impact Research Grant (HIR) Q.J130000.2451.04G54 that enabled the conduct of this research.

\section{References}

[1] Kou, S., Poon, C., \& Wan, H. (2012). Properties of concrete prepared with low-grade recycled aggregates C\&D Waste. Journal of Construction and Building Materials, 36 (2012), 881-889.

[2] National Environment Agency of Singapore. (2019). Waste management statistics and overall recycling measures. Retrieved on March 17, 2020 from https://www.nea.gov.sg/our-services/waste-management/waste-statistics-andoverall-recycling

[3] Pauze, M. (2019). Kompendium Pengurusan Sisa Pepejal Malaysia 2019. Putrajaya: SWCorp.

[4] Sakai, K. \& Noguchi, T. (2013). The Sustainable Use of Concrete. Boca Raton: CRC Press.

[5] Mamlouk, M.S. (2006). Design of Flexible Pavements In Fwa T. F. (ed), The Handbook of Highway Engineering. Arizona: CRC Press, pp 213-247.

[6] Rao, K.V.K. \& Mathew, T.V. (2007). Introduction to Pavement Design In Rao, K.V.K. \& Mathew, T.V. (eds), Introduction to Transportation Engineering. New Delhi: E-Learning.

[7] Giwangkara, G.G., Mohamed, A., Khalid, N.H.A, Nor, H.M., Ahmad, I.S., Ullah, A., et al. (2020). Fibre optic sensing measurement of static surface load distribution on road base layer. IOP Conference Series: Material and Science Engineering, 849, 012045.

[8] Jabatan Kerja Raya (2008). Standard specification for road works. Section 4: flexible pavement. Kuala Lumpur, pp. 1-187.

[9] Leek, C., Siripun, K., Nikraz, H., \& Jitsangiam, P. (2011). An investigation into the performance of recycled concrete aggregate as a base course material in road pavements. Proceeding of International Conference on Advances in Geotechnical Engineering (ICAGE 2011), 343-349.

[10] Leek, C. (2011). Use of Recycled Crushed Demolition Materials as Base and Sub Base in Road Construction. City of Canning: Public Works Department, pp 1-11.

[11] Punmia, C., B., Kumar, J.A., \& Kumar, J.A. (2005). Soil Mechanics and Foundations (16th ed). New Delhi: Laxmi 
Publications (P) Ltd.

[12] Fellenius, B.H. (2006). Basics of Foundation Design. Alberta: BiTech Richmond BC.

[13] Giwangkara, G.G., Mohamed, A., Khalid, N.H.A, Nor, H.M., Hainin, M.R., Jaya, R.P., et al. (2019). Recycled concrete aggregate as a road base material. IOP Conference: Series Material and Science Engineering, 527, 012061.

[14] Roderick, G.L. A History of Particle-Size Limits. Project HR-99. Iowa: Highway Research Board, pp 1-45.

[15] Bhuiyan, M.Z.I., Ali, F.H., \& Salman, F.A. (2015). Application of recycled concrete aggregates as alternative granular infills in hollow segmental block systems. Soils and Foundations, 55(2), 296-303.

[16] Zhu, P., Hao, Y., Liu, H., Wei, D., Liu, S., \& Gu, L. (2019). Durability evaluation of three generations of $100 \%$ repeatedly recycled coarse aggregate concrete. Construction and Building Materials, 210, 442-450.

[17] Giwangkara, G.G., Mohamed, A., Khalid, N.H.A, \& Nor, H.M. (2018). Performance of recycled concrete aggregate as road base material enhanced by polymer waste layer. Proceeding of the 12th SEATUC Symposium - Engineering Education and Research for Sustainable Development, SEATUC, 155-160.

[18] Jabatan Kerja Raya (2013). Manual for the structural design of flexible pavement. Technical Instruction (Road) 5/82. Kuala Lumpur, p. 38

[19] De Beer, M., Sadzik, E.M., Fisher, C., \& Coetzee, C.H. (2005). Tyre-pavement contact stress patterns from the test tyres of the gautrans heavy vehicle simulator (HVS) MK IV+. Proceeding of the 24th Annual Southern African Transport Conference, SATC, pp. 413-430.

[20] Hammel, K. (1994). Soil stress distribution under lugged tires. Soil and Tillage Research, 32 (1994), $163-181$.

[21] Sowers, G.F., \& Vesic, A.B. (1962). Vertical Stresses in subgrades beneath statically loaded flexible pavements. Proceeding of the $41^{\text {st }}$ Annual Meeting Highway Research Board, US Department of Transportation.

[22] Schiffman, R.L. (1961). The influence of Adhesion on the Stresses and Displacements in an Elastic Half-Space. Technical Report CPR-11-0989. Chicago: US Bureau of Public Roads, pp. 17-24.

[23] Koning, H. (1957). Stress distribution in a homogeneous, anisotropic, elastic semi-infinite solid. Proceeding of the 4th International Conference Soil Mechanics and Foundation Engineering, 335-338.

[24] Biot, M.A. (1935). Effect of certain discontinuities on the pressure distribution in a loaded soil. Journal of Applied Physics, 6 (12), 367-375. 